NASA Technical Memorandum 100227

\title{
NASA Supersonic STOVL Propulsion Technology Program
}

\author{
(AASA-TA-100227) NASA SUPERSONIC STOVL \\ PROPOLSION TECHAOLOGY PROGRAB (RASA) 20 P \\ CSCL $21 \mathrm{E}$

Peter G. Batterton and Bernard J. Blaha

Lewis Research Center

Cleveland, Ohio

Prepared for the International Powered Lift Conference sponsored by the Society of Automotive Engineers Santa Clara, California, December 7-10, 1987 
NASA SUPERSONIC STOVL PROPULSION TECHNOLOGY PROGRAM

Peter G. Batterton and Bernard J. Blaha

National Aeronautics and Space Administration

Lewis Research Center

Cleveland, Ohio 44135

\section{ABSTRACT}

Supersonic capable STOVL fighter/attack aircraft can provide capabilities for close support and air superiority which will be highly desirable in the future. Previous papers in this session described the historical aspects, tradeoffs, and requirements for powered 1 ift propulsion systems, and it is shown that propulsion technology is more key to the success of this type of aircraft than for any previous fighter/ $\because$ attack aircraft. This paper discusses the NASA $\infty$ Lewis Research Center program activities which ' address required propulsion technology development. Several elements of this program have been initiated which address hot gas ingestion and ejector augmenter performance and some preliminary results are shown. In addition, some additional near-term research activity plans and the new Powered Lift Facility (PLF) research capability are presented.

\section{INTRODUCTION}

THERE HAVE BEEN FEW successful short takeoff/vertical landing (STOVL) fighter/attack aircraft designs. The most notable success is the AV-8 Harrier. The reasons for the few successes are many, but the obvious ones are that the propulsion system becomes much more complex and considerably more is asked of it. That is, it must provide levels of upward thrust capable of supporting the landing weight of the aircraft and controlling its attitude, yet be capable of switching to provide high levels of forward thrust for normal flight and possibly assisting the flight control. Required weight and volume of the propulsion system may be large, forcing the weight of the total aircraft higher, and ultimately resulting in an undesirable aircraft design. The conclusion is that for a supersonic capable STOVL aircraft, advanced propulsion technology is the key to allowing it to happen $(1,2) *$.

It has always been a goal of NASA Aeronautics Research to address and resolve high risk, long lead technologies. An attempt to design a current advanced, supersonic cruise capable STOVL fighter aircraft would lead to the conclusion that the required propulsion technologies are not available. Further, demonstration of these technologies will be required before the DoD and industry will attempt even a prototype. Therefore, the overall goal of the program and projects described in this paper is to have the propulsion technology in place to permit the low risk initiation of a research STOVL supersonic fighter/attack aircraft in the early-to-mid$1990^{\prime} \mathrm{s}$. This paper describes the elements of the NASA Lewis Research Center program directed toward achieving this goal.

\section{REQUIRED PROPULSION TECHNOLOGIES}

There are five basic approaches to STOVL propulsion currently being considered. These are:

(1) Vectored Thrust - e.g., the AV-8 Harrier, which uses a separate flow bypass engine supplying nozzles forward and aft of the aircraft center of gravity (CG).

(2) Ejector Augmenter - a concept with an airflow augmenting ejector located forward of the CG with primary air provided by the engine fan bypass.

(3) Remote Augmenter Lift System - a concept with burners and nozzles located remotely from the engine and forward of the CG and which use air provided by the engine fan bypass.

*Numbers in parentheses designate references at end of paper. 
(4) Tandem Fan - a variable cycle engine concept in which the fan stages can be separated so that the front stage provides air for nozzles forward of the CG for vertical mode. The front stage supercharges the aft fan stage for normal flight.

(5) Lift + Lift/Cruise - e.g., the YAK-36, a concept which uses a separate lift engine forward of the $C G$ during vertical thrust mode of operation. This engine is used at this time only.

There are many other propulsion concepts as well, but these can be considered as hybrids of the five just described.

Many of these propulsion concepts share technology requirements with supermaneuverable fighters. It is anticipated that in the end, these two capabilities, STOVL and supermanueverablity, will be combined. For example, the short take-off requirement can easily lead to the use of a vectoring nozzle capability, such as $\pm 20^{\circ}$. This is basically the same requirement of supermaneuverable aircraft with propulsive (vectored thrust) flight controls. Both types of aircraft require high thrust to aircraft weight ratio propulsion systems. And both types of aircraft require fully integrated flight and propulsion controls to achieve the desired levels of performance.

The propulsion technology needs cover a broad spectrum and fall into seven basic catagories :

(1) Propulsive Lift Concepts

(2) High Thrust-to-Weight Ratio Engines and the Impact of Attitude Control System Bleed

(3) Supersonic Inlets with High Angle-ofAt tack and Low Speed Capability

(4) Lightweight, Modulating, Deflecting, and Vectoring Nozzles

(5) Efficient Low Loss Ducts, Valves, and Fan Air Collectors

(6) Hot Gas Ingestion Avoidance/ Accommodation

(7) Integrated Flight/Propulsion Controls

Some of these are being addressed in other on-going NASA and Air Force technology programs. The high thrust-to-weight ratio engine technology is being addressed by the Integrated High Performance Turbine Engine Technology (IHPTET) Program. The use of vectoring nozzles for propulsive control and high angle-of-attack inlets are being addressed on the NASA F-18 High Angle of Attack Research Vehicle (HARV) Program at NASA Ames-Dryden and the DARPA/Navy Enhanced Fighter Maneuverability (EFM) Program.

The remaining technical requirements will likely be developed under a supersonic STOVL program. Issues specific to the propulsive lift concepts such as performance, efficiency, weight and volume must be resolved. The impact and availability of compressor bleed air for attitude control from the high performance core engines is an unknown. The supersonic inlets will not only have to operate at high angles-of-attack but at very low speed and with shorter diffusers than current design practice. Many of the concepts use internal ducting, valves, and fan air collectors which must be as compact as possible yet be highly efficient and light weight. As the aircraft approaches the ground for vertical landing, some of its own exhaust will be pushed forward of the aircraft and potentially ingested by the air intake system. This hot gas must be accommodated with minimal vertical thrust loss. And finally, pilot work load must be managed to acceptable levels allowing pilots to reasonably fly the aircraft in all its modes of operation, including transition where the propulsion system begins to replace the aerodynamic controls. In hover of course, the propulsion system must serve as the flight control system.

Figure 1 shows the overall program elements that have been initiated or are planned for initiation in the near future. Because the favored propulsion concept has not been identified, if it can ever be, the current technology research activities tend to be focused on "common technology" issues, i.e., technologies that apply to a number of the propulsion concepts. The only exception to this is a desire to establish a technology base for the ejector concept which has a history of unsatifactory full-scale performance (3), but has the desirable feature the lowest temperature footprint.

The six program elements are Fan Air Collectors, Valves, Ducting, and Ejectors; Hot Gas Ingestion; Short Diffuser Supersonic Inlets with High Angle-of-Attack Capability; Integrated Flight/Propulsion Controls; Thrust Augmentation by Burning; and Thrust Deflecting and Vectoring Nozzles. The first four of these efforts are currently being pursued at NASA Lewis. The last two are planned for initiation as resources can be developed. In general, each of these program elements has both analytical and experimental phases. The program and results to date are now described for the four active elements.

FAN AIR COLLECTORS, VALVES, DUCTING, AND EJECTORS

U.S./CANADA PROGRAM - The research activities associated with fan air collectors, valves, ducting, and ejectors is being accomplished in the joint U.S./Canada Ejector Program. NASA, the Canadian Government, deHavilland, and General Dynamics (GD) have for a number of years been highly interested in demonstrating the ejector propulsive lift concept. More recently, DARPA has also provided support to the concept. At NASA Lewis, we are addressing not only the ejector performance, but also the performance of the engine to ejector air delivery system. Figure 2 shows the basic concept being evaluated under the program, which is the GD's E-7 conceptual aircraft with ejectors developed by deHavilland. The concept has all thrust aft for normal flight, then for vertical mode the fan bypass air is ducted forward to power an ejector located in the wing roots. This program provided the strong impetus to develop the new Powered Lift Facility (PLF), which uses a research air supply 
system to evaluate full scale STOVL components in a static, ground environment.

POWERED LIFT FACILITY - The new Powered Lift Facility (PLF), shown in Fig. 3, was initially designed and built to support the U.S./Canada Program. The system includes a large triangular ( $30 \mathrm{ft}$ on a side) frame supported $15 \mathrm{ft}$ above the ground. This frame is supported by load cells which provide a six component force measuring system. Vertical (20 $000 \mathrm{lb})$, axial (30000 1b), and lateral (5000 lb) forces as well as pitch, roll, and yaw moments can be measured in both positive and negative directions. High pressure (to $95 \mathrm{psig}$ ) and heated (to $300^{\circ} \mathrm{F}$ ) air with flows greater than $160 \mathrm{lb} / \mathrm{sec}$ can be supplied on the stand to simulate fan bypass air. The air is brought onto the system through a series of bellows, oriented at $90^{\circ}$ to the force system, to minimize air delivery system momentum tare forces. The facility was completed and flow tests were initiated in September 1986. Initial force calibrations were made in April 1987, and performance tests began in June 1987.

As stated above, the PLF was initially designed to support the U.S./Canada Ejector Program. However, it is completely suitable for evaluation of components for all of the supersonic STOVL propulsion concepts. It also could be used as a static test facility for multi-axis nozzle systems for supermaneuverable aircraft.

EJECTOR PERFORMANCE - The first major research activity on the PLF was the evaluation of the deHavilland ejector. This followed an evaluation of the flow delivery system and the calibration of the thrust measuring system.

Figure 4 shows the test ejector installed on the PLF and some of the more significant results. The upper photo is a view looking at the diffuser downstream end of the ejector. The lower photo is looking at the inlet of the ejector secondary with the primary nozzles clearly visable. By no means a small scale model test, the test ejector measures approximately $10 \mathrm{ft}$ by $2 \mathrm{ft}$ and is supplied by $42 \mathrm{lb} / \mathrm{sec}$ primary airflow at the design point. The ejector achieved $3300 \mathrm{lb}$ of thrust at that condition.

The results are shown on the right in

Fig. 4. Augmentation ratios ranged between 1.6 and 1.8 over the primary nozzle pressure ratios of interest. For this plot, augmentation ratio is defined as the total gross thrust divided by the ideal primary thrust calculated with primary nozzle total pressure. If the flow delivery system loss based on the PLF results is included, the resulting thrust augmentation ratio would be reduced by approximately 3 percent. The results also agreed quite well with the deHavilland test, and for both cases exceeded the design minimum installed augmentation ratio requirement of 1.6 at a primary nozzle pressure ratio of 2.5 . The measured augmentation ratio will be reduced slightly when installation and primary flow system losses are included.

The next step in U.S./Canada Ejector Program will be the evaluation of the E-7 model in the Ames Research Center 40- by 80-ft wind tunnel. Based on the results obtained on the PLF, confidence in the success of this program is high. Follow-on work for the PLF will include a static evaluation of the E-7 model with the ejectors, evaluation of alternate ejectors, and an integrated flight/propulsion control system. This latter item will be discussed below.

\section{HOT GAS INGESTION}

Hot gas ingestion (HGI) has, of course, been addressed in earlier V/STOL programs, including the AV-8 Harrier (4). Solutions usually are, however, custom tailored compromises, leaving little technical data or methodology base. Figure 5 is introduced to show the complexity of the Hot Gas Ingestion (HGI) problem. The two major phenomena that occur are the near field and far field effects which are caused by fountain upwash and separated ground flow respectively. In near field effect, the fountain upwash essentially is the desired reflection of the jet exhaust off the ground upon the underside of the aircraft which increases 1 ift by off-setting suck-down effects. However, this hot gas can run along the underside of the fuselage and enter the engine inlet system, producing a temperature distortion to the engine, loss of thrust, and at worst an engine compressor stall. In far field effect, the hot exhaust proceeds along the ground until surface wind or buoyancy separates it. It can then be ingested by the engine inlet system. This will again result in a loss of thrust due to the elevated inlet temperature.

ANALYTICAL APPROACH - Analytical modeling of the situation described above has been initiated, which is shown in Fig. 6. The objective of the analytical effort is to assemble and validate three-dimensional computer codes which could ultimately be used to predict inlet distortion. The figure shows a simple aircraft fuselage with inlets and exhaust nozzles representative of a vectored thrust type of STOVL aircraft using the four post exhaust nozzle configuration. For the model, the inlet mass flow rate is matched to the exhaust nozzle flow rate. The results shown are based on a three-dimensional incompressible Navier-Stokes computation using the "Teach Code" of Imperial College, and, therefore, should be considered as qualitative only (5).

Plane 4 temperature contours represent the ground plane, with flow proceeding from the top in the contour plots to the bottom. Because of symmetry around the centerline of the aircraft fuselage, only half of the environment is calculated and shown. Even though the exhaust velocity is roughly ten times the bulk flow velocity, at the ground plane the flow is swept down stream. Plane 3 is located at roughly the mid point between the fuselage and the ground plane, and shows the development of the fountain between the exhaust nozzles. Plane 2 is the undersurface of the fuselage and shows the concentration of hot gas between the nozzles. It also shows hot gas flow proceeding upstream toward the inlets. Plane 1 is at the level of the bottom of the inlet duct, and shows a streak of hot gas being 
ingested. Qualitatively, this is about what one would expect to see.

SCALE MODEL RESEARCH - To obtain model data for the purpose of assessing HGI and distortion which must be accommodated by an engine and evaluation of approaches for avoiding HGI, a 1/10 scale model experimental research program has been established. This is a joint effort with NASA, DARPA, and McDonnel1 Douglas Aircraft (MCAIR) as partners. Figure 7 shows installa$t$ ion of the MCAIR 279-3 model in the NASA Lewis 9- by 15-Ft Low Speed Wind Tunnel (ISWT). The model is mounted at the end of a long support arm which contains the ducting for inlet airflow exhaust system. External to the tunnel is a heater system which provide hot gas to the exhaust nozzles. Flow and temperature to the nozzles can be individually controlled. The photo on the right in the figure shows a close-up of the model and the trap door in the ground plane below it. The purpose of the trap door is to allow removal of hot exhaust gas from the test section while setting up conditions. This avoids preheating the ground plane and the underside of the model which could cause erroneous results. Once model conditions are set, the trap door closes in less than one second and data is acquired.

Figure 8 provides one set of preliminary results obtained from the test setup pictured in Fig. 7. Conditions were nozzle pressure ratio of 3.0 and exhaust gas temperature of $500^{\circ} \mathrm{F}$. Heights are expressed in feet for a full scale aircraft rather in model scale to give a better perception to the result. Basically, the data show that free stream velocity had little effect and the hot gas ingestion did not result in significant temperature rise for equivalent landing gear heights greater than $1.13 \mathrm{ft}$, where temperature increase was approximately $10^{\circ} \mathrm{F}$ or less. However, these results are for $500^{\circ} \mathrm{F}$ exhaust gas temperature. Other scaling laws must yet be applied to determine the severity of the hot gas ingestion for this configuration.

\section{SUPERSONIC INLET WITH SHORT DIFFUSER}

Inlets for supersonic STOVL aircraft must provide high performance while addressing the special configuration integration problems. The basic configurations for the aircraft tend to have the engine(s) located closer to the aircraft center of gravity than conventional fighters. This results in less length available for the supersonic inlet diffuser. For a given throat to diffuser area ratio, this results in a steeper wall angle and hence greater probability of separation. The goal of this study is to achieve a diffuser area ratio of 2.0 with a diffuser length to diameter ratio of 1.25 as opposed to a more typical length to diameter ratio of 4.0 . This short diffuser design is guaranteed to separate, as depicted in the plot in the lower right of Fig. 9, unless some type of diffuser boundary layer control is successfully validated. An analytical study was performed (6) to determine methods of diffuser boundary layer control and thus avold separation. These methods will be evaluated with this inlet design. Once a suitable boundary layer control technique has been validated, the same concept could also be applied to high angle-of-attack inlet operation where separation may also be a problem.

ANALYTICAL RESULT - Figure 10 shows the results from the short diffuser analysis. Separation occurs at approximately 0.6 normalized length $\left(X / L_{C}\right)$ where the skin friction coefficient approaches zero. The analysis showed that with a nominal bleed design, separation could be avoided. The amount of bleed is shown in the lower left and the resulting skin friction is shown as the dashed line on the lower right plot. Also studied was the usefulness of blowing to energize the boundary layer and the amount of required engine bleed air to supply the blowing system. These results were then used as the basis for a design of a short diffuser inlet model which could be used to validate the analysis.

DIFFUSER HARDWARE - A new diffuser section for an existing two-dimensional NASA Lewis/MCAIR inlet model has been fabricated. A photograph of it is shown in Fig. 11. The diffuser is designed to have a length to diameter equivalent to 1.25 . It can accommodate various concepts for boundary layer control including suction holes, discrete blowing nozzles, and distributed blowing slots, as well as more conventional vortex generators. This hardware is currently being instrumented and is planned for evaluation at low speed and angle-of-attack in late 1988 .

\section{INTEGRATED FLIGHT/PROPULSION CONTROLS}

One of the key issues associated with supersonic STOVL will be integration of the flight and propulsion control systems. The aircraft goals require integration of supersonic flight, highly maneuverable flight, short take-ofe and vertical landing. These modes of flight all are different and require different control strategies to implement. A pilot in combat cannot be expected to deal with all the, i.e, modes, hence the interest in developing integrated flight/propulsion control system. NASA Lewis and Ames, and DARPA have recently initiated a program to demonstrate an approach to integrating the controls. The initial effort is an extension of the U.S.l Canada Ejector Program because the characteristics of this system are most clearly known. Also participating are GE, GD, Systems Control Technology, and dellavilland. The overall objective is to evaluate the Design Methodology for Integrated Control Systems (DMICS) $(7,8)$ as extended to STOVL from CTOL. The goal is the successful closed-loop demonstration of an operational engine with ejector augmenter and simulated aircraft. Evaluation of the control logic in a piloted simulator is also being planned.

Figure 12 depicts schematically the basic propulsion hardware arrangement for the control evaluation. Although the control logic is being evaluated on an ejector based system, the number of control loops, nonlinearities, etc., that must 
be dealt with are typical of any of the STOVL propulsion concepts. All new digital control logic will address the Lift Operating Mode, Cruise Operating Mode, and Transition Between Mode. The ground based test hardware will be mated to a GE F110 type engine modified to include a variable vane valve, ventral nozzle, and vectorable two-dimensional convergent/divergent (two-dimensional-CD) nozzle. Again these items are typical of many of the STOVL propulsion concepts. The propulsion system will be evaluated on the Lewis PLF in conjunction with a real-time aircraft simulation running in parallel, and will focus on vertical and transition operation. Inputs to the engine and aircraft simulation will include a pilot in the 1oop. This program will be accomplished in 1989, and will be followed by a further evaluation of the ejector concept powered by an F110 in the NASA Ames 40- by 80-Ft Wind Tunnel.

\section{HOW IT COMES TOGETHER}

One of the problems about discussing a program such as this is multiplicity of activities. Figure 13 is one notion of how these efforts can all be tied together. As stated in the beginning of this paper, the goal was to put the technologies in place that allow a low risk initiation of a supersonic research aircraft. Such an aircraft requires demonstration of viable propulsion technologies. There are four main thrusts supporting this goal. This includes the on-going NASA and DoD Base Research and Technology specifically addressing high thrust-to-weight ratio engines and the inlet research described above. It also includes the U.S./U.K. ASTOVL Program with its Concept Studies, Common and Concept Specific Technology Plans, and the U.S./Canada Ejector Program. These include the remainder of the items addressed in this paper. Finally, it includes studying the application of derivatives of advanced engines currently planned for the DoD inventory at about the time a research demonstrator would be considered. Here, jointly with DARPA and the Air Force, the control system requirement is also being assessed, because this is such a long lead item.

\section{CONCLUDING REMARKS}

As stated at the beginning of this paper, propulsion is key to the development of a supersonic STOVL fighter/attack aircraft. NASA Lewis has developed a plan that addresses the required technologies. For the elements that have been initiated, preliminary successes have been achieved. New facilities and research capabilities have also been developed which w1ll be useful to not only this effort but others such as highly maneuverable fighter aircraft.

Considerable interest has developed outside of NASA as well. The DoD, specifically DARPA, is a strong supporter of research for STOVL propulsion. Interest at the Air Force has grown substantially with their involvement in the advanced engines and controls. Both the U.K. and Canadian Governments are strong participants in STOVL propulsion.

With adequate resources, considerable progress can be expected over the next several years, thus allowing supersonic STOVL to be a promising candidate for future fighter/attack aircraft.

\section{REFERENCES}

1. G.H. Kidwel1 Jr, and B.A. Lampkin, "An Evaluation of Supersonic STOVL Technology," AIAA Paper 83-2493, Oct. 1983.

2. W.J. Lewis and D. Palfreyman, "Supersonic V/STOL Ready for Technology Push," Aerospace America, Vol. 22, Oct. 1984, pp. 46-51.

3. P.A. Bevilaqua, "Advances in Ejector Thrust Augmentation," AIAA Paper 84-2425, Oct. 1984.

4. W.J. Lewis and R. Hurd, "Augmented Vectored Thrust Engines and the Problem of Avoiding Hot Gas Recirculation," ASME Paper 79-GT-10, Mar. 1979.

5. T.W. Bruce, H.C. Mongia, and R.S. Reynolds, "Combustor Design Criteria Validation," Vo1. 1, USARTL-TR-78-55A, Mar. 1979.

6. D.P. Hwang, "Analytical Study of Blowing Boundary-Layer Control for Subsonic V/STOL Inlets," Computation of Internal Flows; Methods and Applications, P.M. Sockol and K.N. Ghia, eds., ASME, New York, 1984 , pp. 151-157. (NASA TM-83576).

7. K.I. Smith, W.B. Kerr, and G.L. Hartmann, "Design Methods for Integrated Control Systems," AFWAL-TR-84-2088, Dec. 1984.

8. D.S. Joshi, P.D. Shaw, S.M. Rock, and W.S.C. Fisk, "Design Methods for Integrated Control Systems," AFWAL-TR-84-2037, Feb. 1985. 


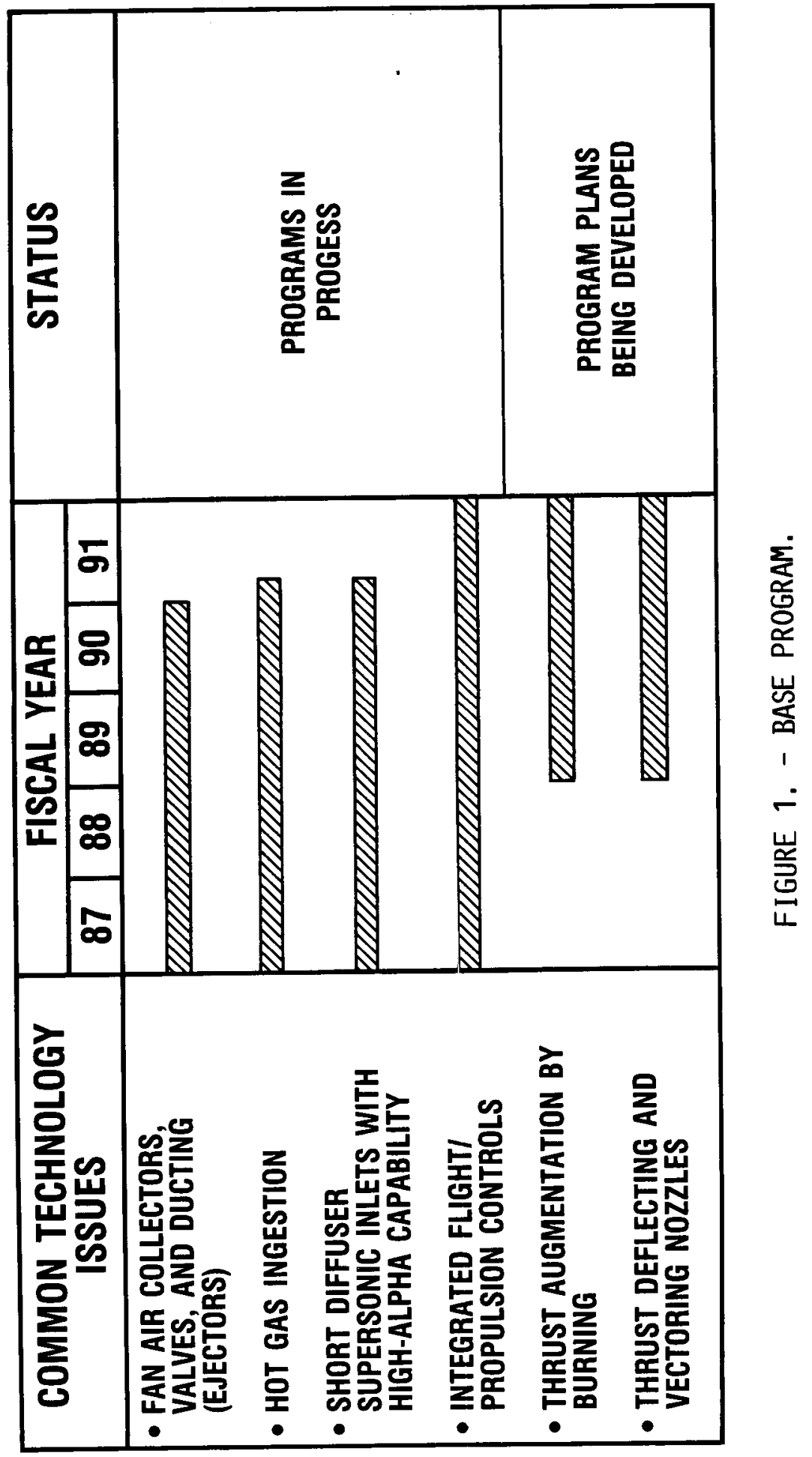




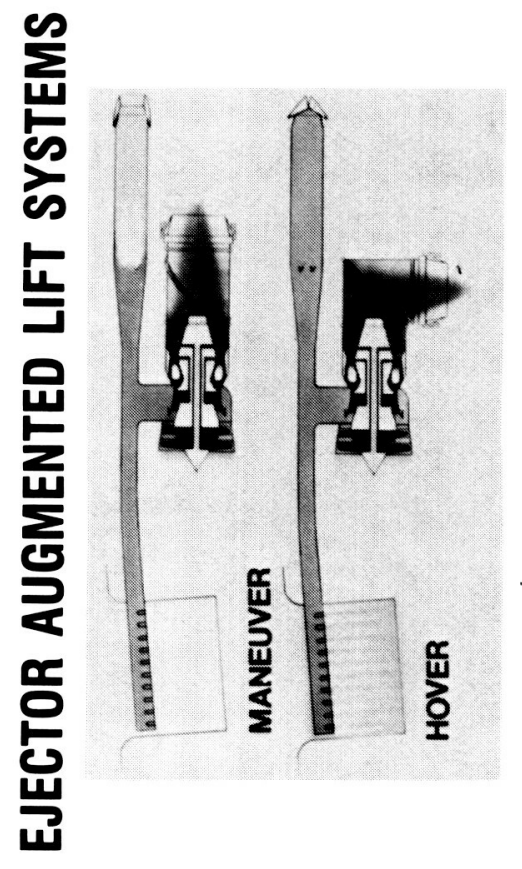

DRIGINAL PAGE IS

OF POOR QUALITY

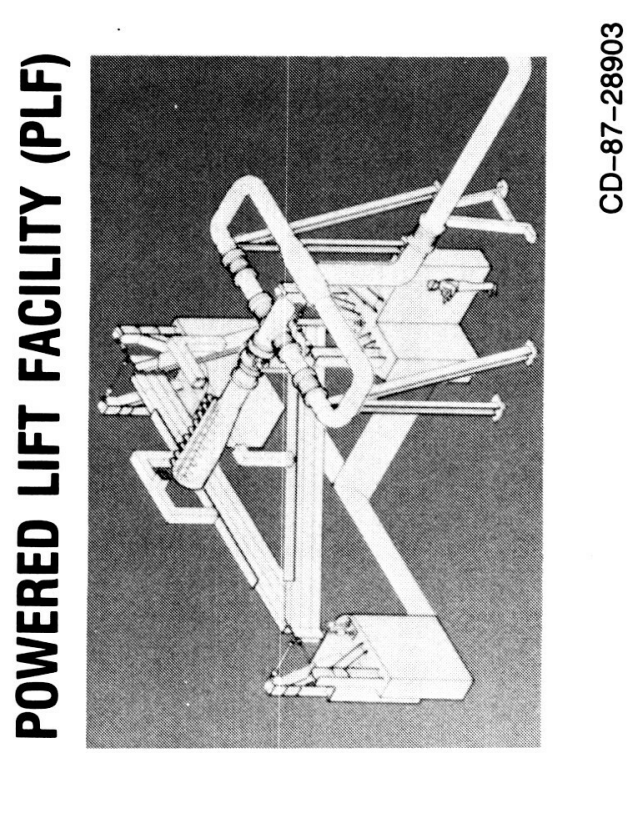

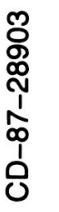
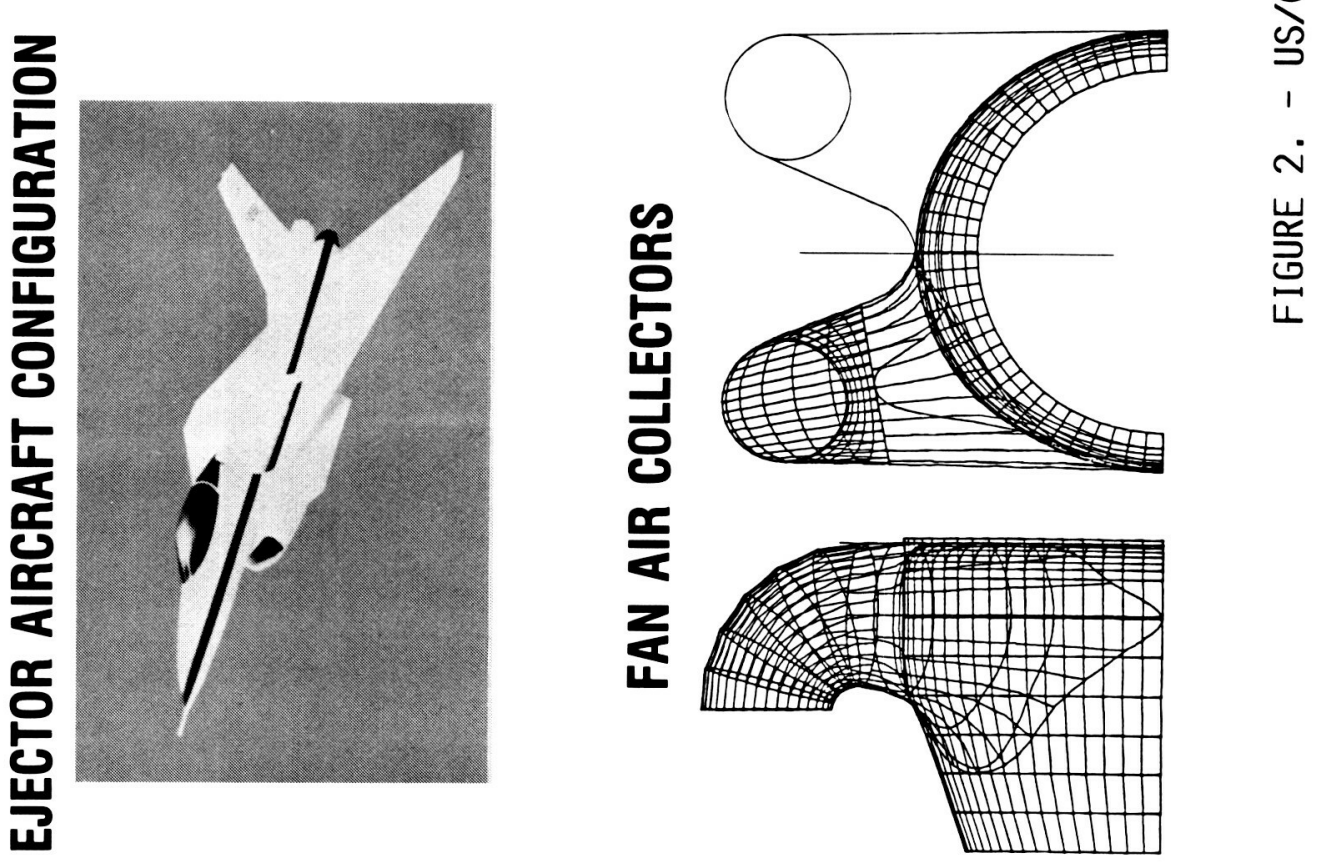
ORIGINAL PAGE IS

OF POOR QUALITY

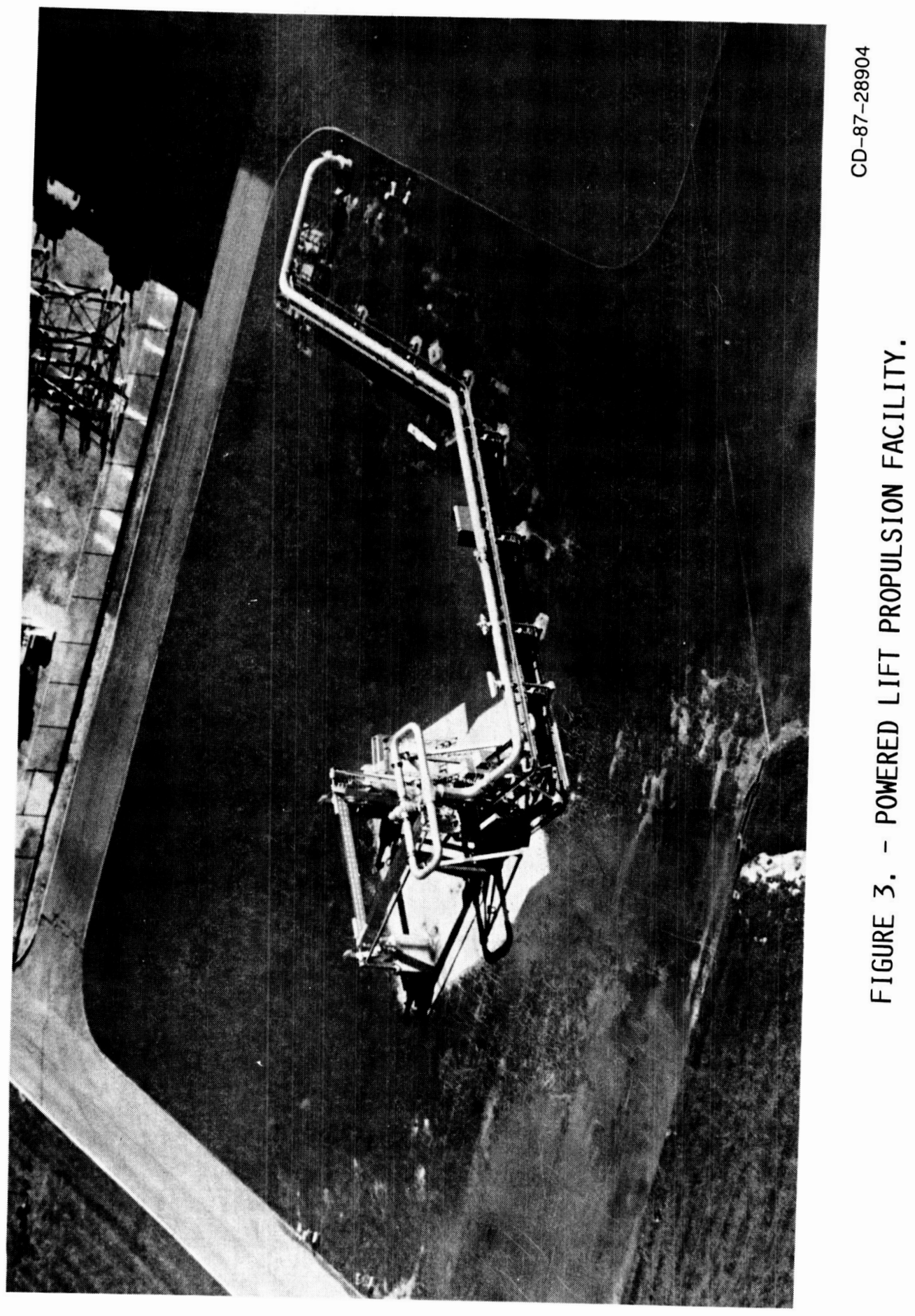




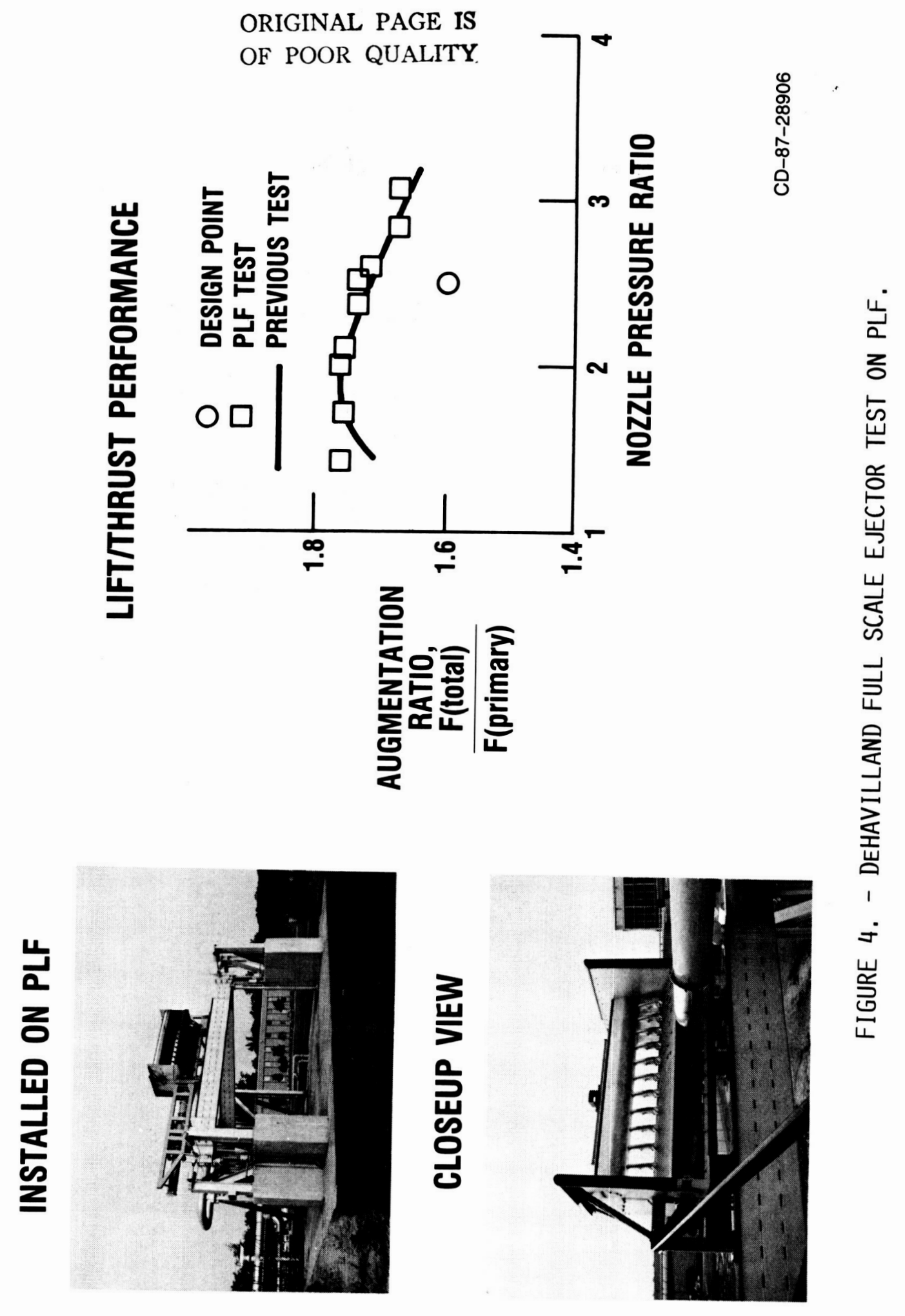




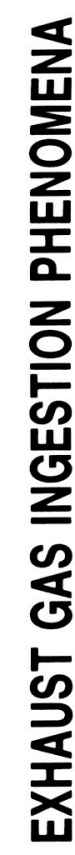
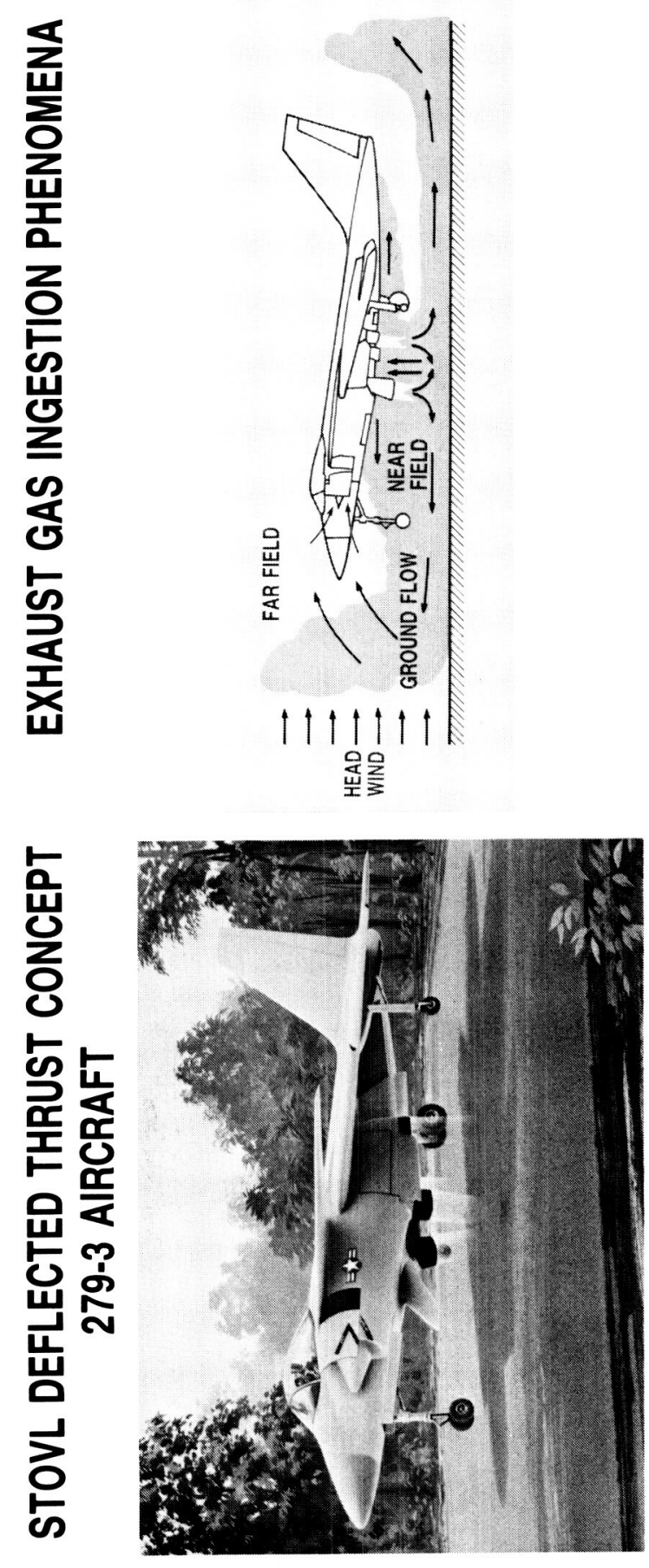
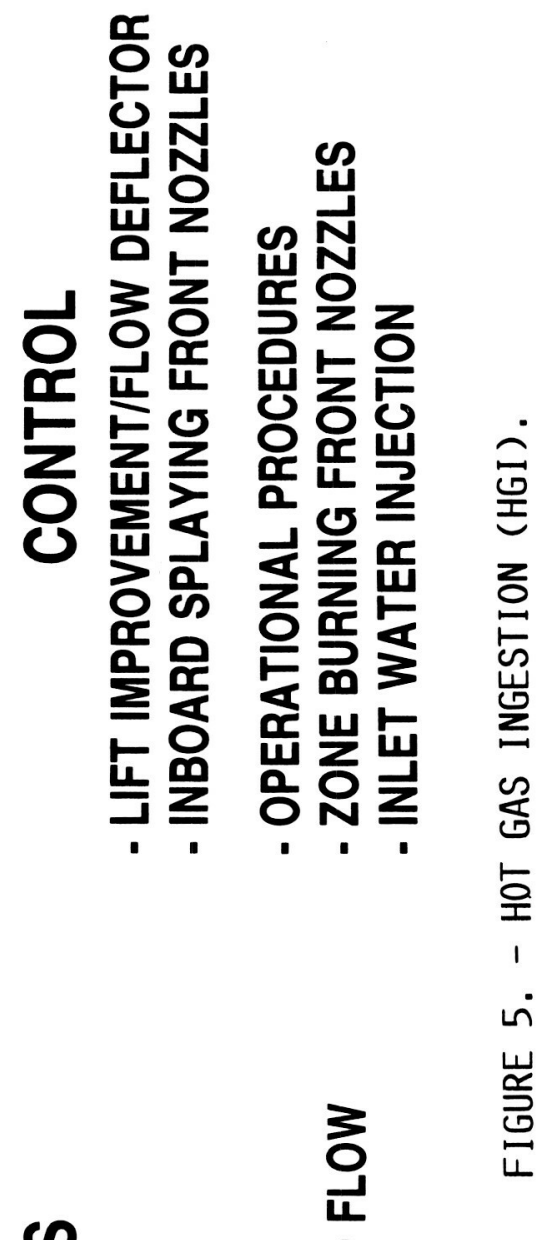

0
4
0
0

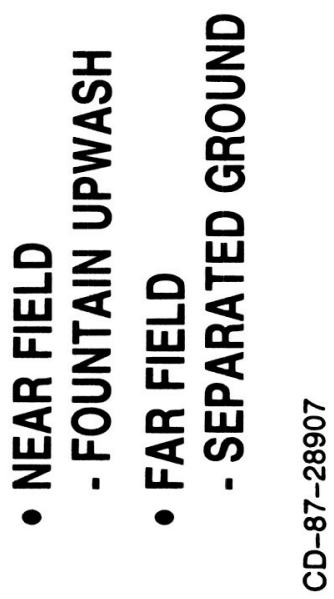


ORIGINAL PAGE IS

OF POOR QUALITY
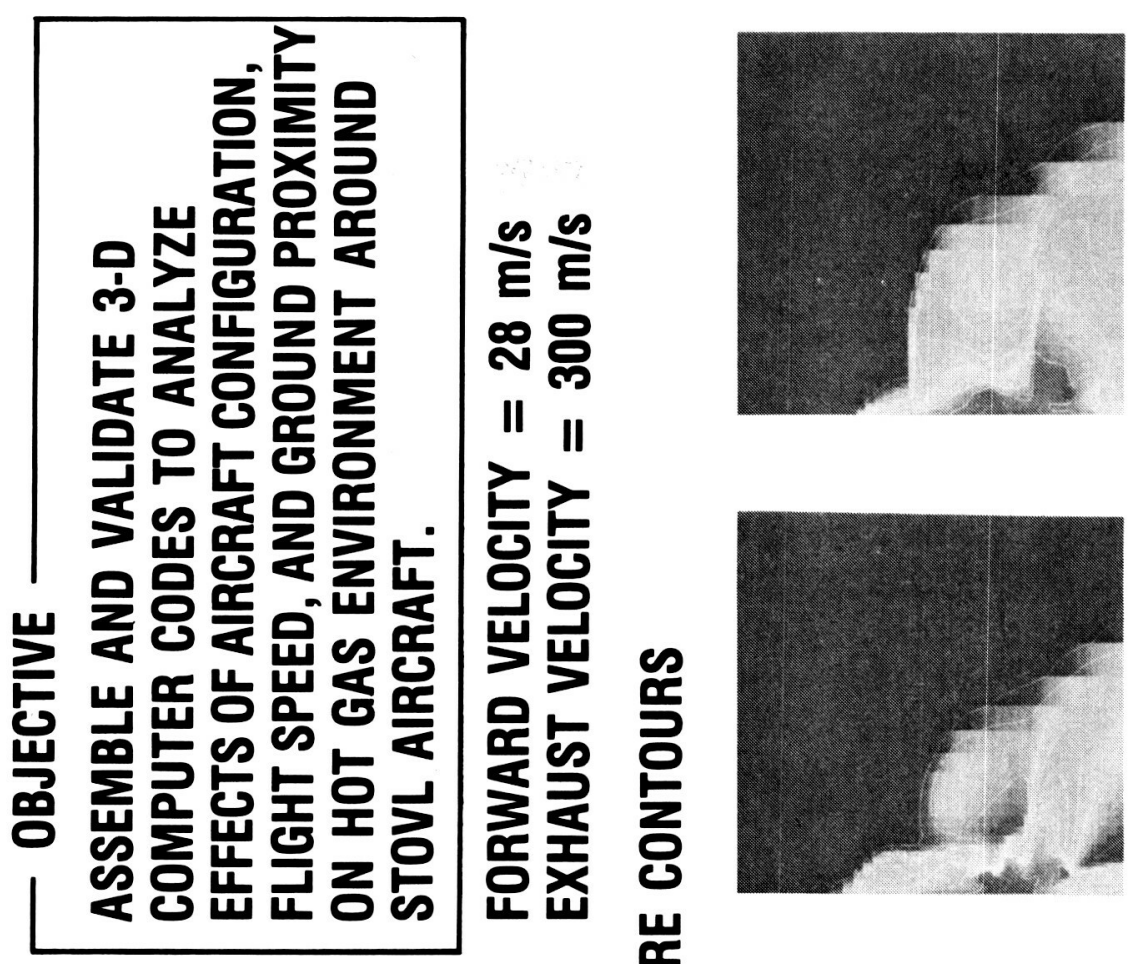

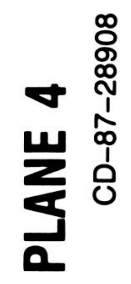
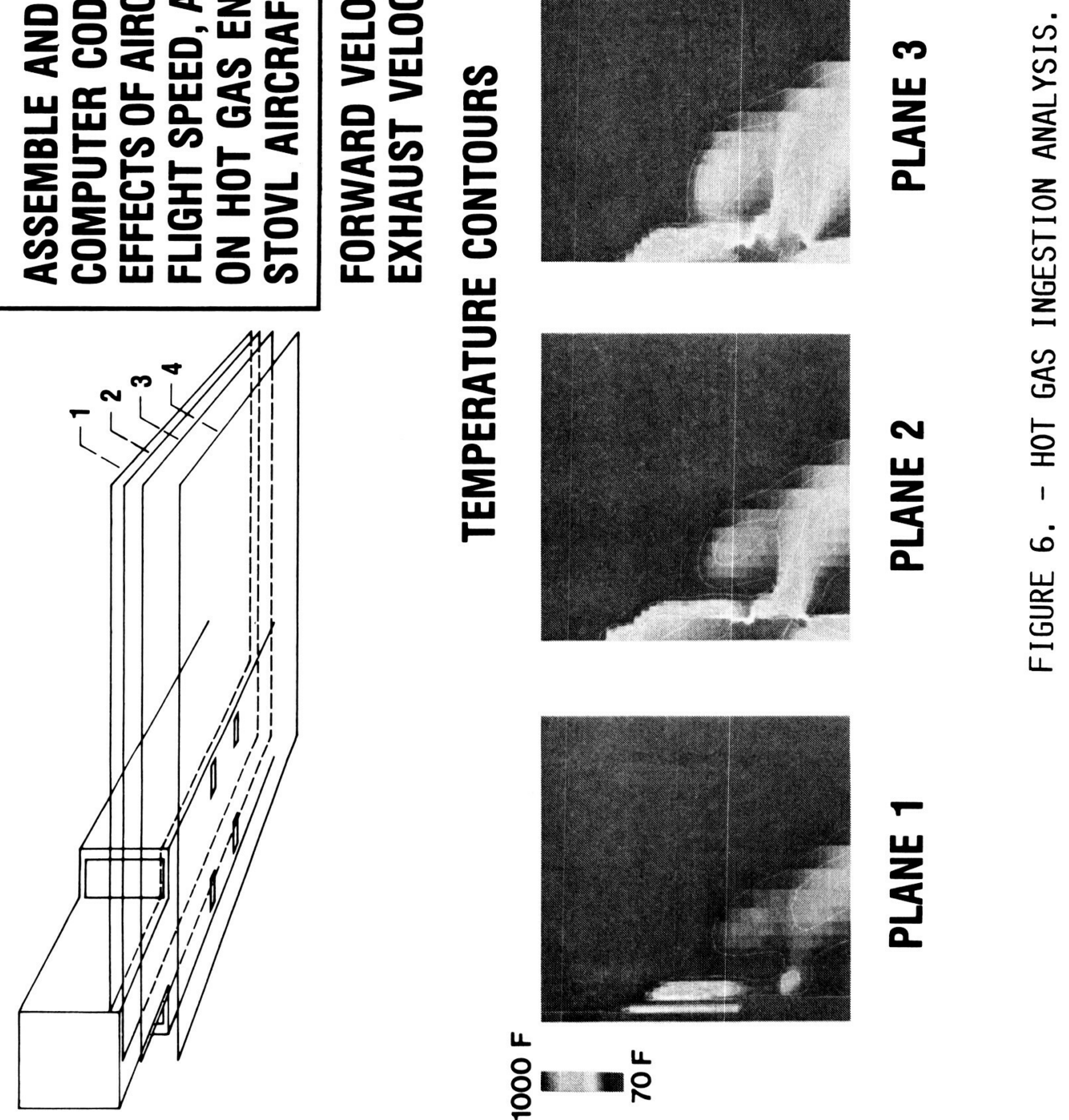

는
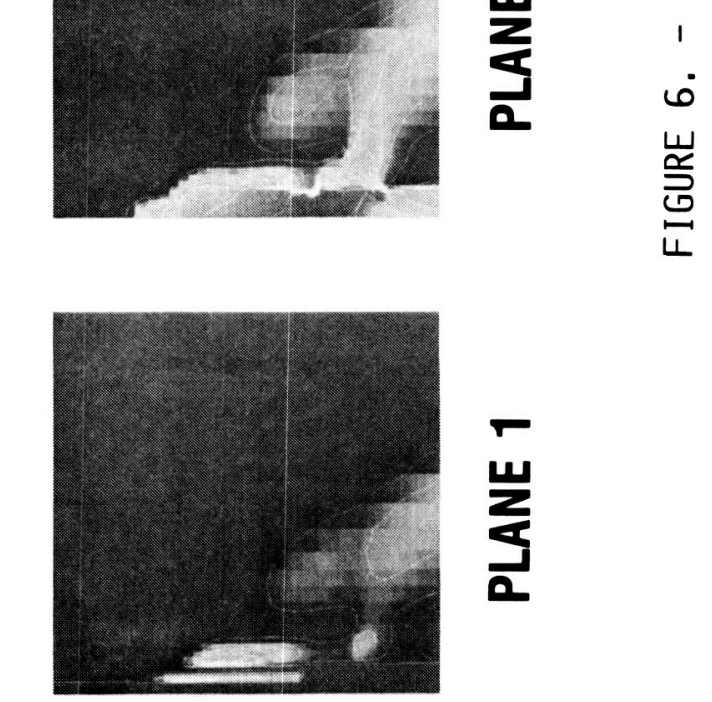

풀

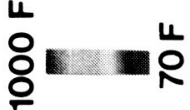




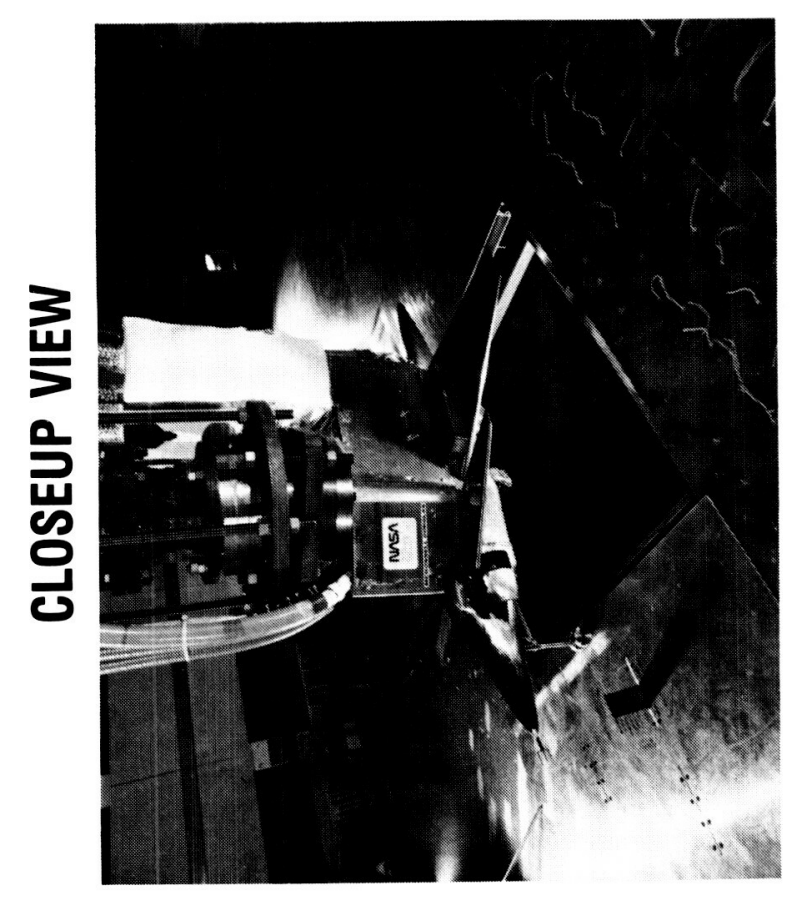

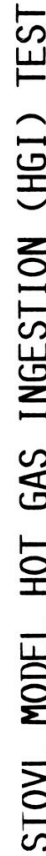

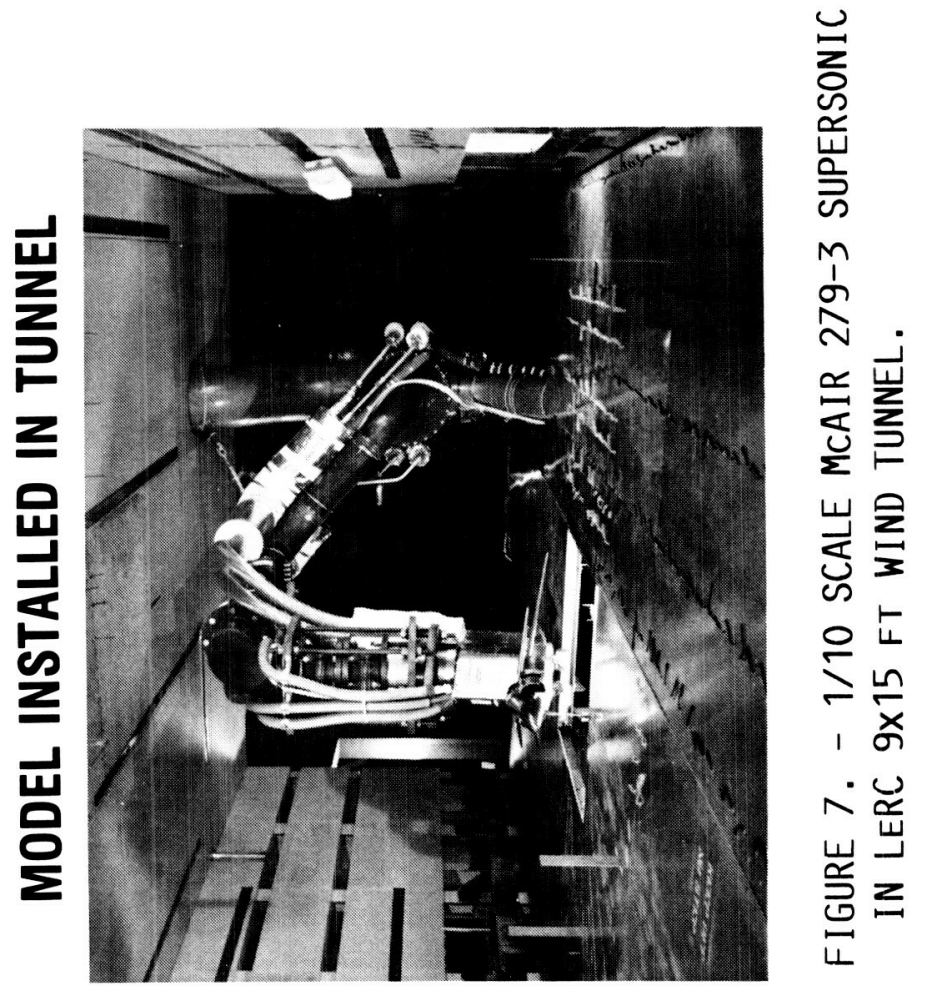

ORIGINAL PAGE IS

OF POOR QUALITY 


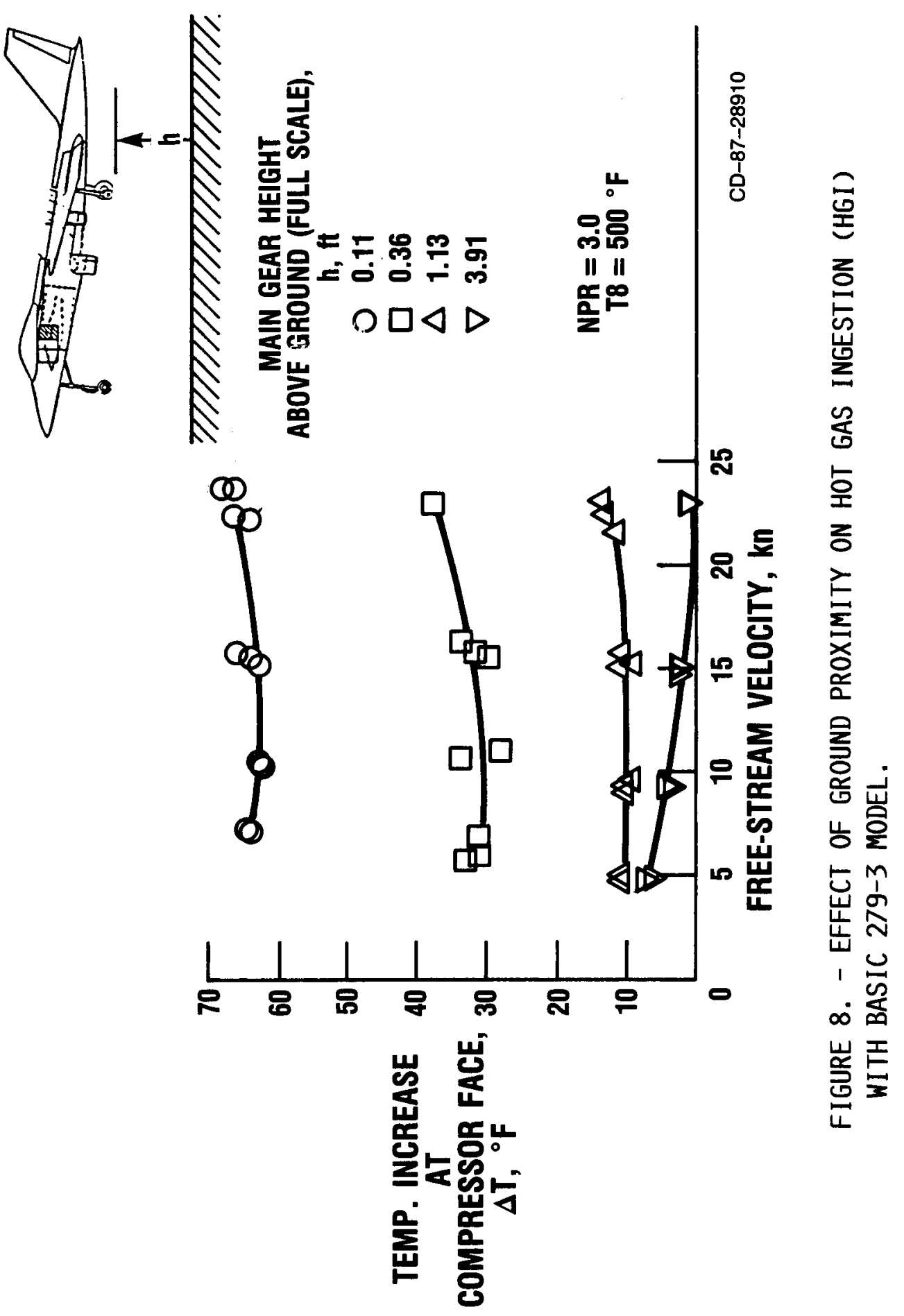


ORIGINAL PAGE IS

OF POOR QUALITY
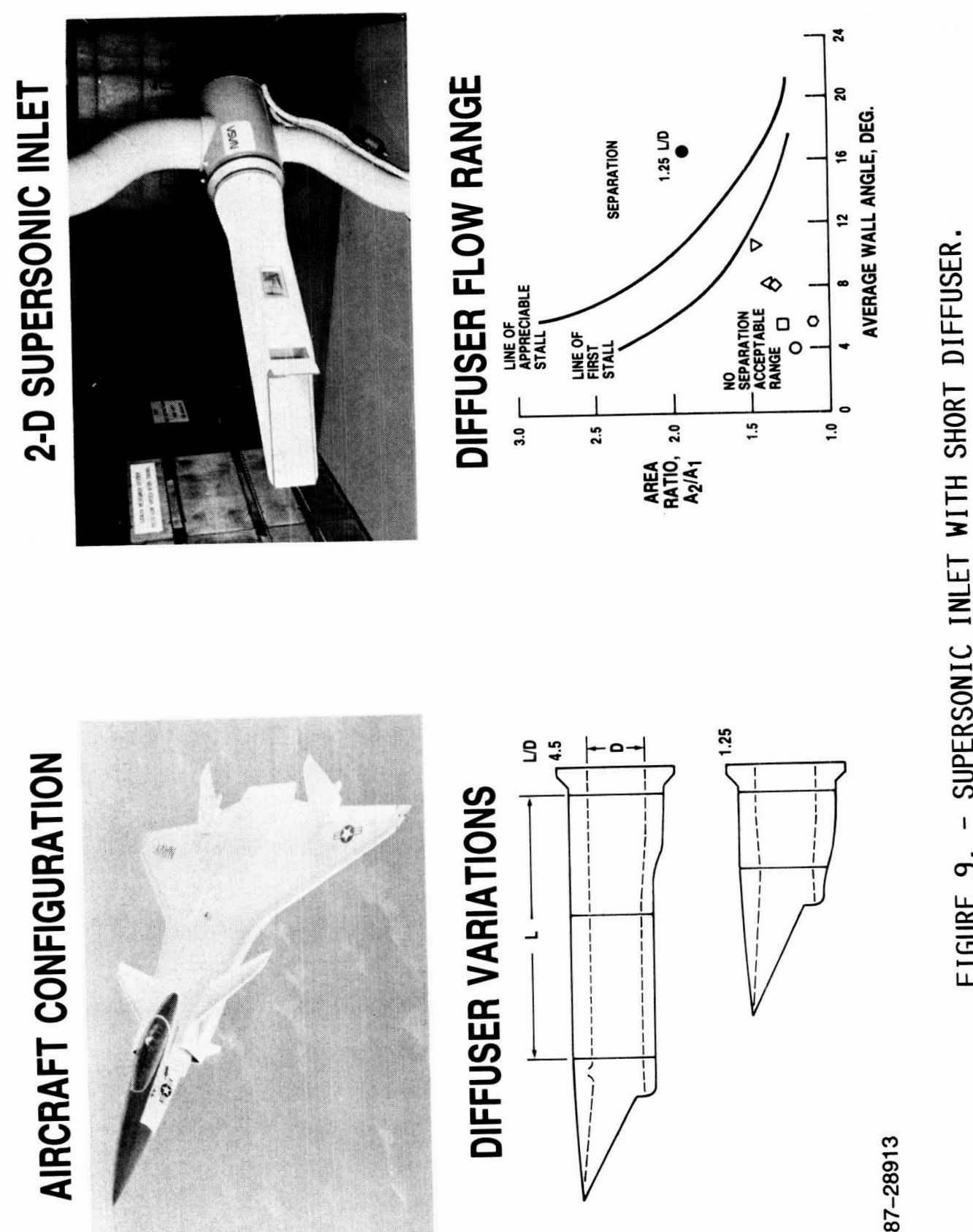

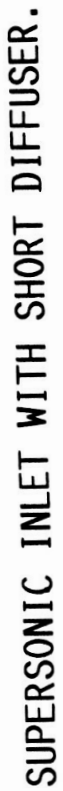

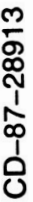



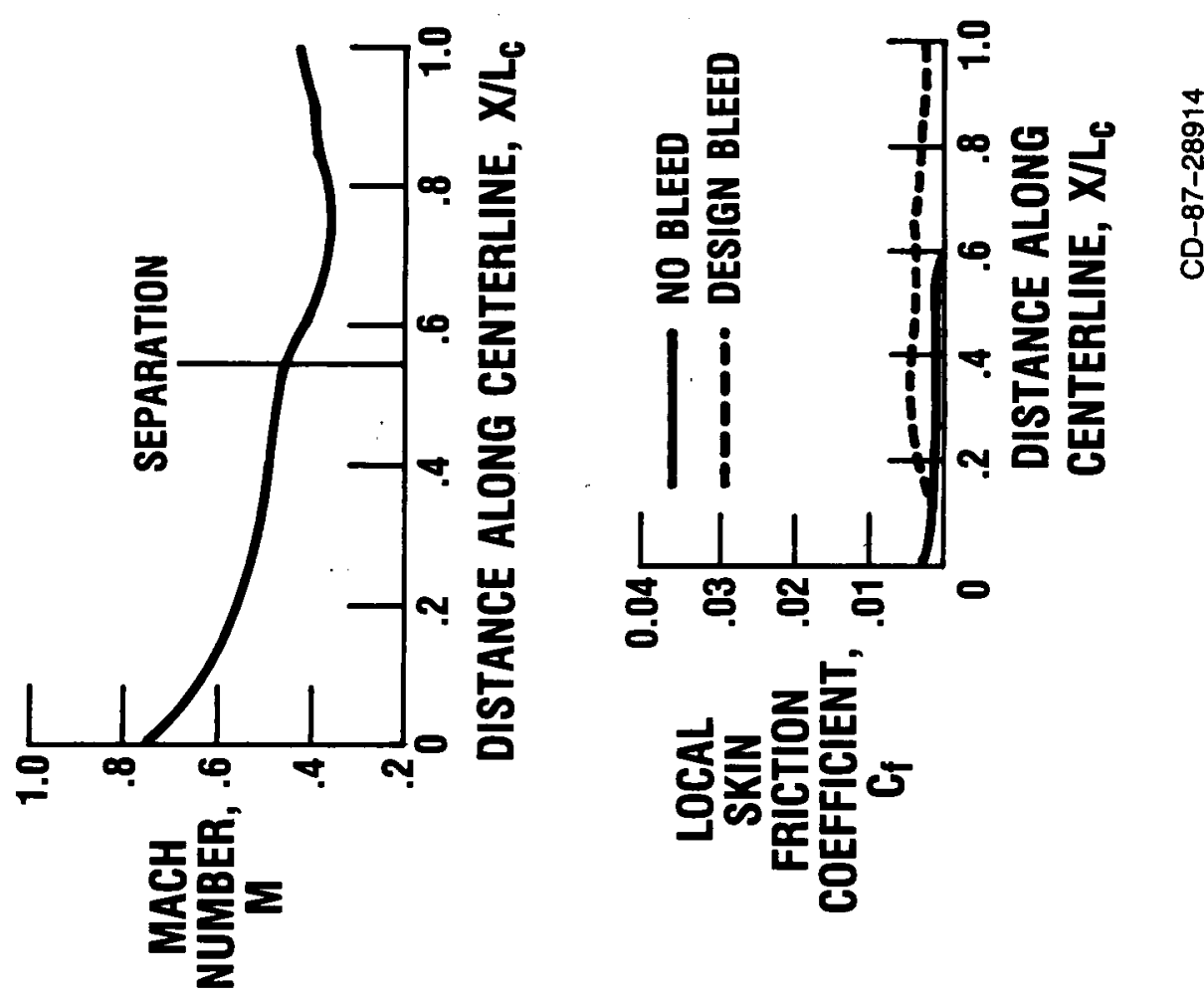

次
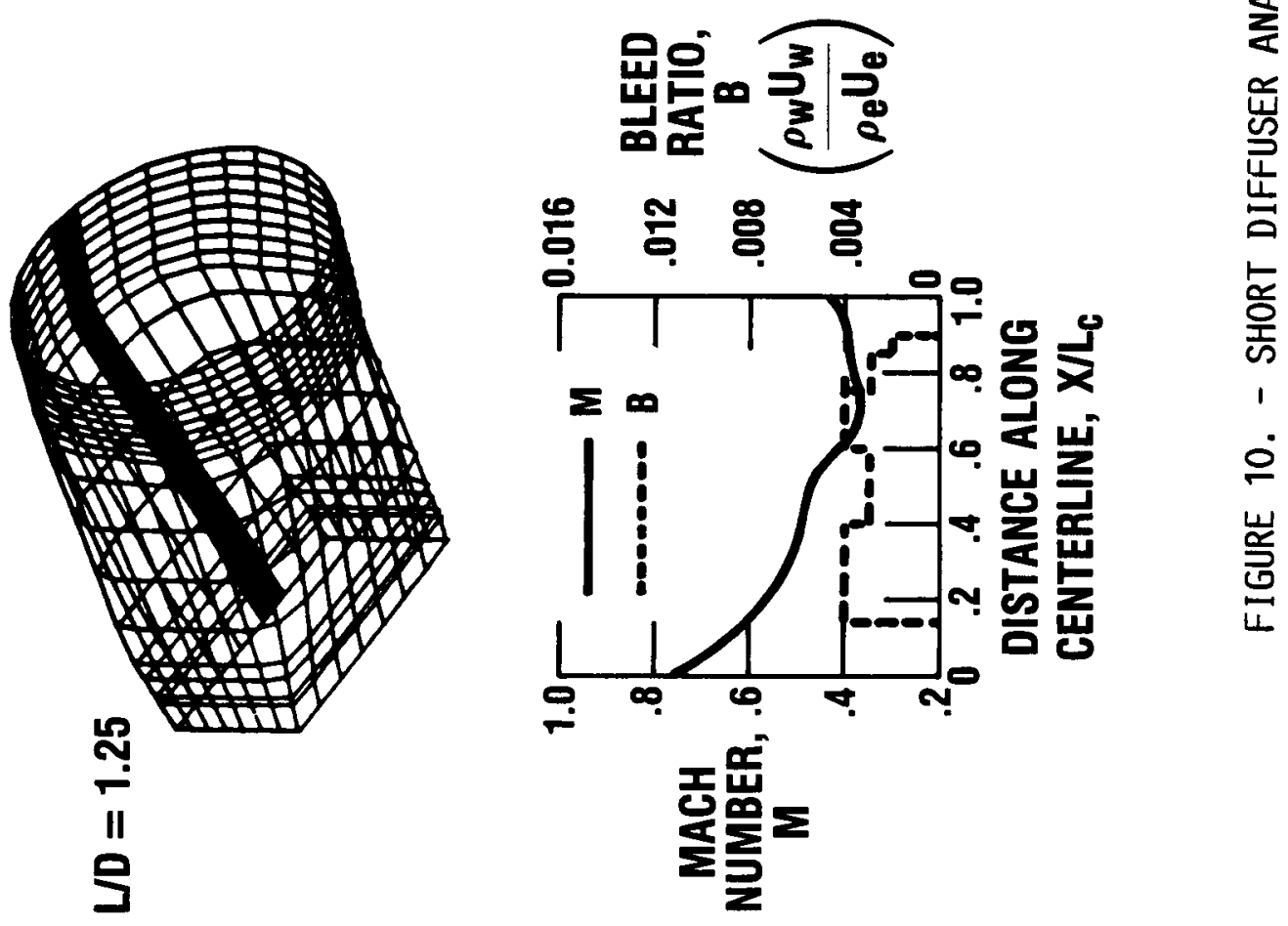
ORIGINAL PAGE IS

OF POOR QUALITY

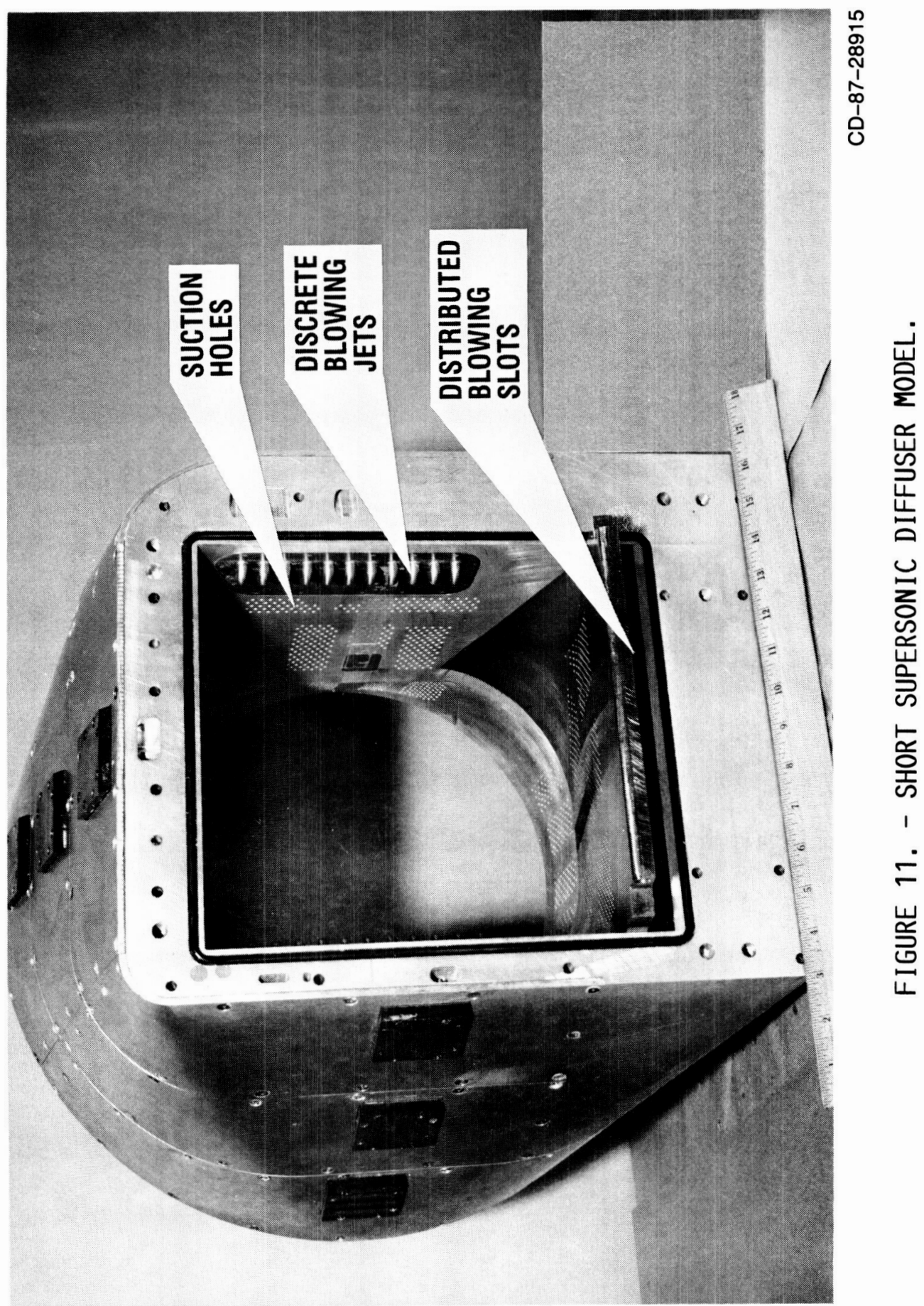




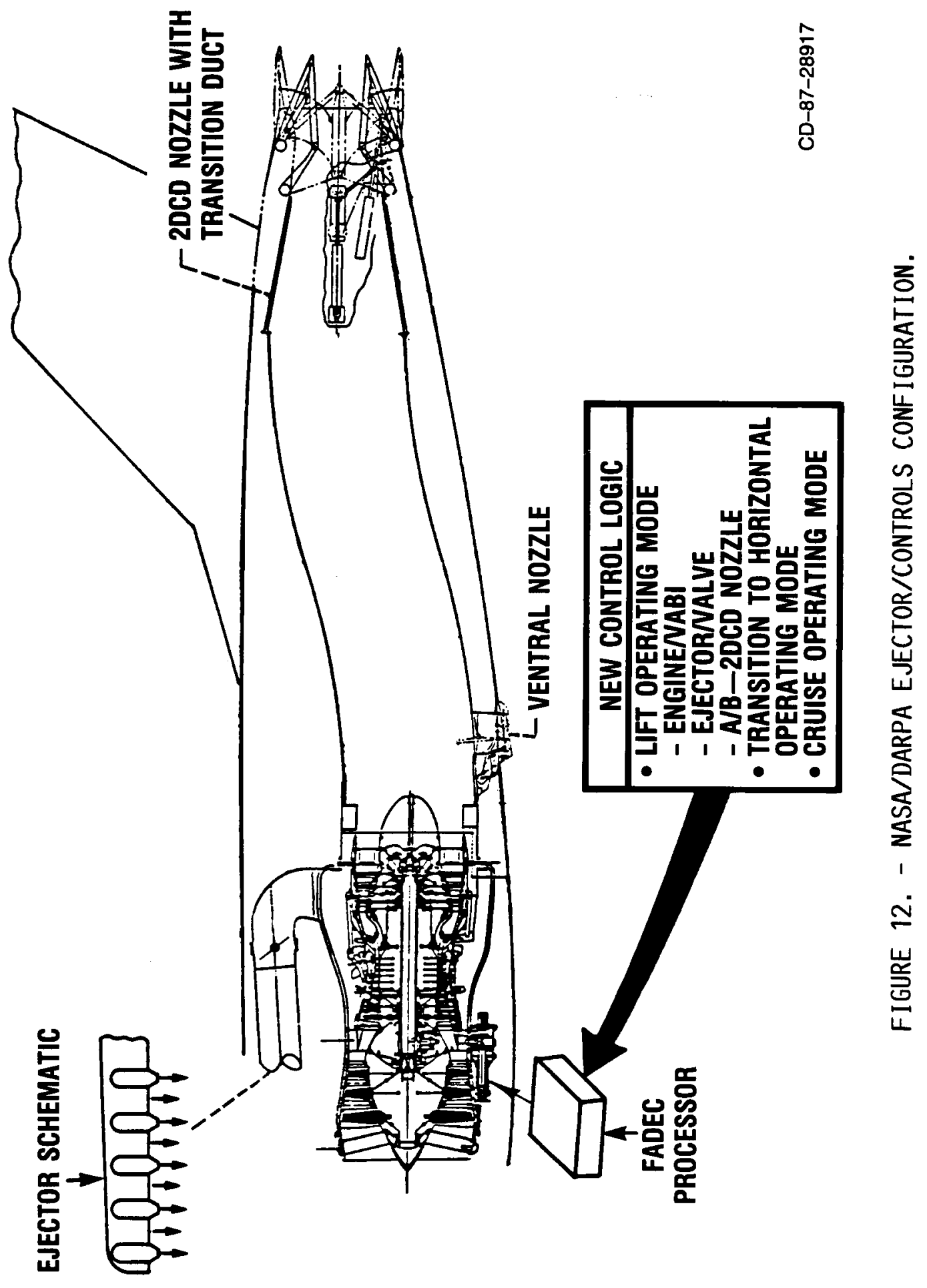




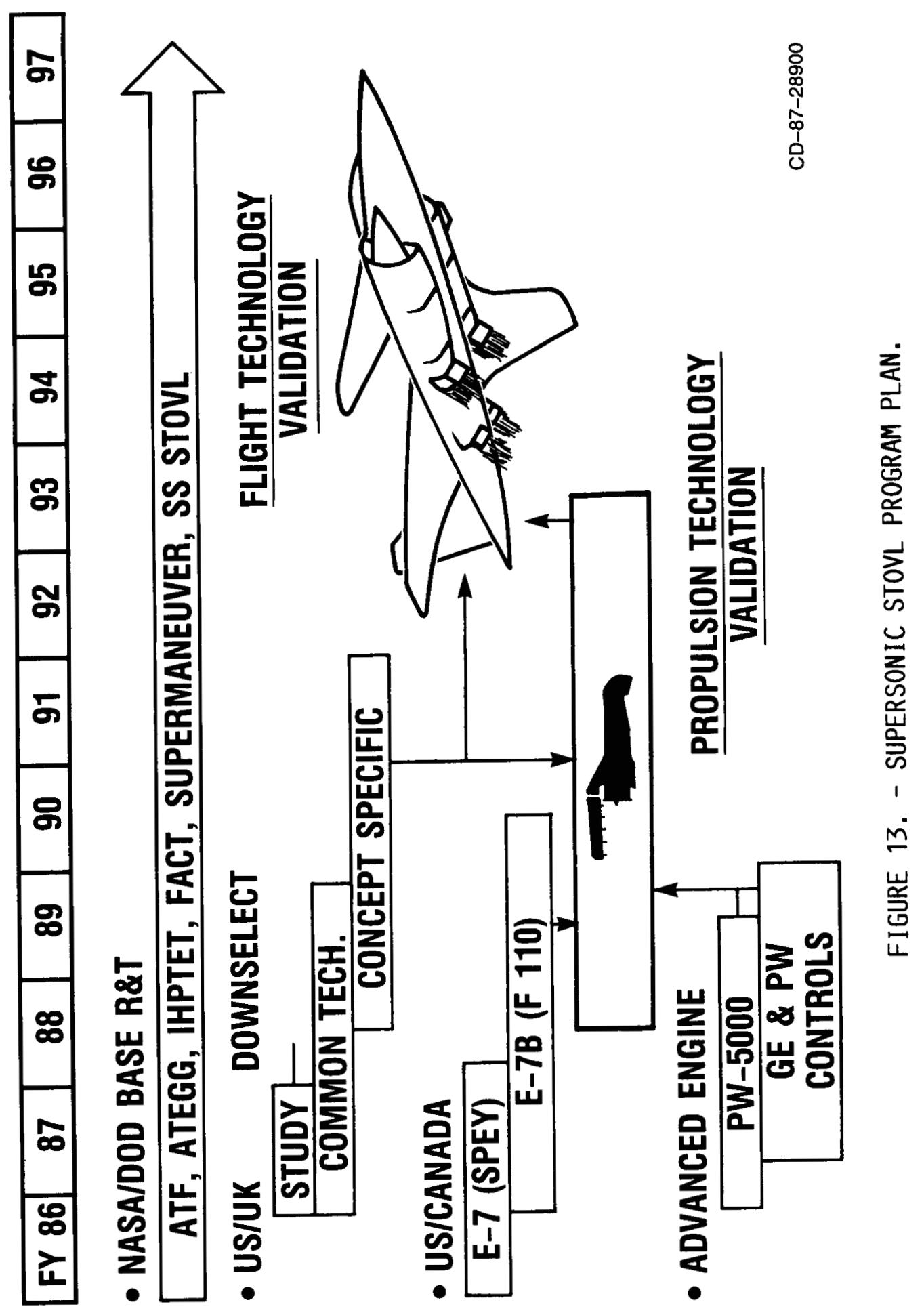




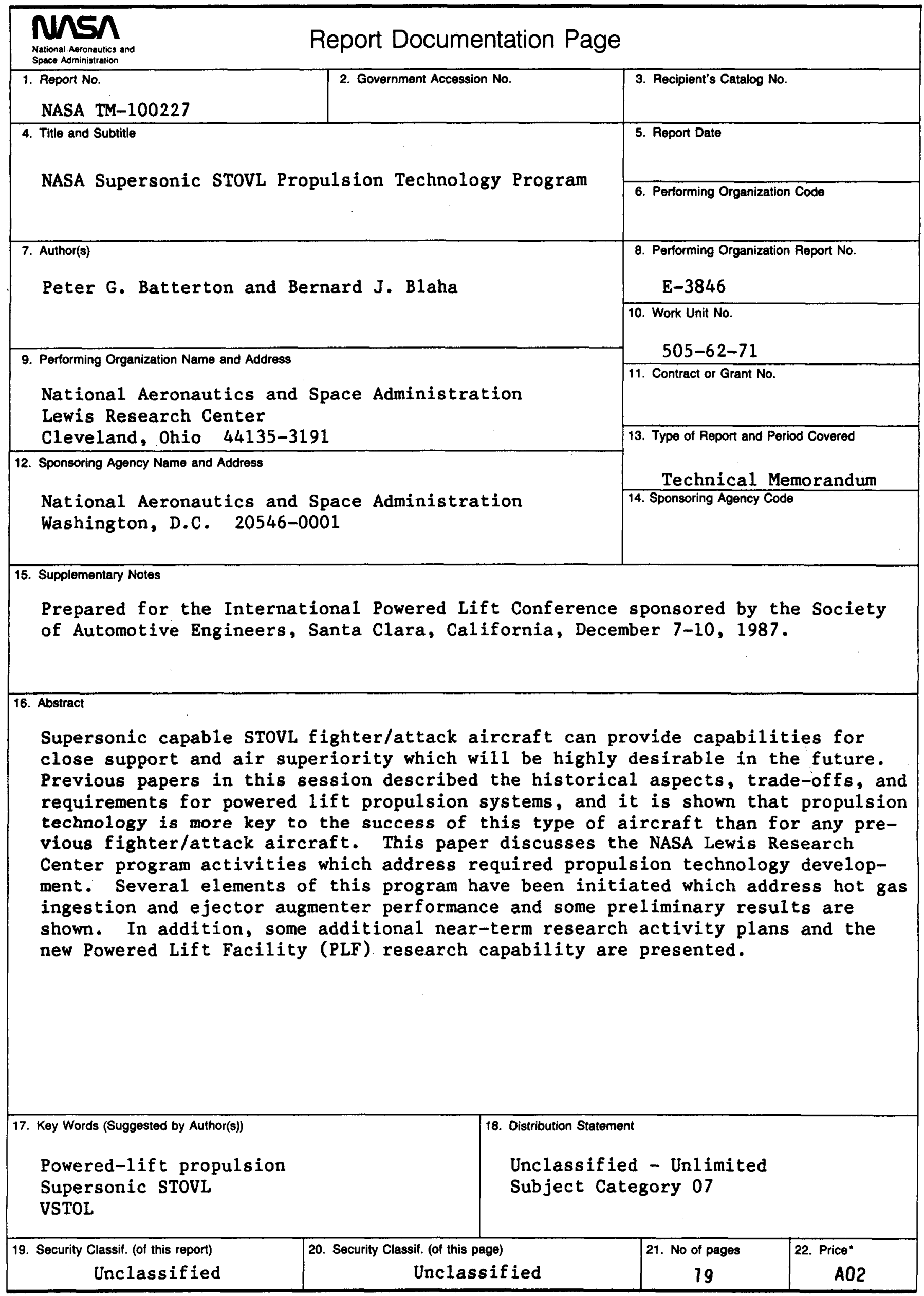

NASA FORM 1626 OCT B6 *For sale by the National Technical Information Service, Springfield, Virginia 22161 